\title{
ELECTRICAL CONTACTS
}

\begin{abstract}
A
SYMPOSIUM on "Electrical Contacts", organized by the Institute of Physics and the Physical Society, in collaboration with the Institution of Electrical Engineers, was held during April 5-7, at Brunel College of Technology. The membership was limited to some 260 by the accommodation only, and interest in the subject was such that acceptances were closed some weeks before the date of the symposium, which, although not meant to be international in character, was, nevertheless, attended by representatives from a dozen different countries. The subject under consideration, being of fundamental scientific interest as well as of obvious practical significance, proved itself to be of concern to physicists, engineers, metallurgists and chemists from both industrial and Government research establishments as well as universities. The symposium was so arranged that the main aspects of electrical contact phenomena could be discussed in some detail in separate sessions.
\end{abstract}

The opening session consisted of an address by Prof. F. Llewellyn Jones (University College of Swansea) on "The Physics of Electrical Contact Phenomena", in which the main aspects of contact operation were surveyed, and the important problems of fundamental significance indicated, as well as the methods by which they are now being attacked in the various laboratories. The sessions which followed each consisted of between four and six short papers grouped under the headings: principles, fundamental investigations and techniques, contact surfaces, methods and design, non-metallic contacts, and miscellaneous subjects. Each session included a discussion. In this brief communication it is not possible to give an account of all twenty-five papers in detail; $a$ fuller report is being published in the British Journal of Applied Physics. This notice will be confined to comments on the scope of the discussion and the general conclusions reached.

The opening survey address considered the whole contact operation from the initial approach to the final separation of the electrodes, in the order in which the events usually take place. The aspects concerning fundamental physics and some of the problems still unsolved were pointed out. For example, the behaviour of a contact just before the electrodes actually touch ( $\sim 10^{-4} \mathrm{~cm}$. apart) involves interesting problems of surface physics relating to the electrical activity of surfaces due to the presence of thin films. Attention was also directed to the interesting and varied phenomena associated with molten, and possibly boiling, metal in the microseopic region of contact. In this connexion, contact physics can make a contribution to our knowledge of the properties of metals at high temperatures in the molten state. A ciné-film was exhibited, showing the quasi-static molten metal bridge passing through a series of mathematically predictable shapes before sudden breaking. The establishment of a micro-arc immediately on the breaking of the bridge was then considered, and the possibility of ionic transfer in the high-temperature plasma pointed out. Finally, the importance of surface films was referred to in the operation of very light-duty contacts with negligible currents-the electro-static contacts.

In the second session dealing with principles, the theme of the properties of metals at high tempera. tures was further developed by Dr. M. R. Hopkins (University College of Swansea). Thermal instability in a contact was discussed by Dr. J. B. P. Williamson (Cavendish Laboratory and Tube Investments, Ltd., Cambridge). Because of the importance of the nature and behaviour of surface films on contact electrodes (continually emphasized during this conference), the mechanism of formation of oxide films on metals was considered by Dr. O. Kubaschewski (National Physical Laboratory). Interest in nonmetals was illustrated by a paper on the friction and wear of graphitic and non-graphitic carbon in which the important rule of adsorbed layers was stressed by Dr. J. W. Midgley (English Electric, Ltd., Leicester).

In the third session, the different techniques of investigations of the various aspects of contact operation were described. P. E. Watts (Associated Electrical Industries, Aldermaston) showed how the effect of temperature asymmetry on matter transfer was being investigated, while Dr. C. H. Jones (Royal Marsden Hospital) described the work done at the Department of Physics, University College of Swansea, using radioactive tracer techniques for the measurement of metal transfer. This sensitive method enables the transfer in an opening contact to be measured. with very low series inductances, and it was concluded that transfer in platinum, palladium and silver was not independent of the micro-arc discharge. Dr. A. Fairweather (Post Office Research Station) illustrated the properties of the mechanical deformation of contact electrodes at closure by means of models in two-colour laminated 'Plasticene'. He showed that different forces produce geometrically similar indentations, and that the flow-patterns depend on frictional constraints.

Most of the remainder of the session was devoted to the properties of contact surfaces. The practical aspects of very light-duty electrical contacts were assessed in a review paper by Dr. J. C. Chaston (Johnson Matthey, Ltd., London). From the practical point of view of design and manufacture important factors were electrode shape and material, surface finish, contact-loading force, and in particular the separating force and freedom from bounce.

The cleanliness of precious metal surfaces was discussed by H. C. Angus, while Dr. W. Betteridge (both of International Nickel Co. (Mond), London) considered the operation of extremely light-duty contacts at high temperatures. For example, at temperatures of $500^{\circ} \mathrm{C}$. contact, operation can become difficult because of oxidation, welding and thermoelectric effects. So far as noble metals are concerned, investigations show that gold and platinum are film-free, but that ruthenium has a highly conducting oxide. Electro-deposition of metals was described in some detail by F. H. Reed (International Nickel Co. (Mond), London), and other papers provoked much further discussion on this topic. Quanti- 
tative assessment of electrode activity due to surface films was described by E. B. Pattinson (Department of Physics, University College of Swansea) and the influence of dust on contacts was considered by Dr. J. A. Greenwood (Tube Investments, Ltd., Cambridge). Dr. Fairweather discussed the effects of plastic lubricants and the behaviour of granular materials. With these materials, energy losses depend not only on the properties of the material but also on granule dimensions and the structure of the granular boundaries. A description of recent contact research in Japan was given by Prof. G. Matsumoto (Tohoku University). The properties of electrodes of silver-nickel and silver-metallic oxides, produced by powder metallurgy, were described, as well as work on arc suppression by electro-chemical treatment of the electrode surfaces. The selection of electrical contact materials for light-duty applications was surveyed by Dr. V. G. Morradian (Engelhard Industries Inc., New Jersey). The proceedings closed with a summary by Dr. M. R. Hopkins.

The last conference on electrical contacts in Britain was held in 1952 (see Nature, 169, 960; 1952), and it is interesting to consider the developments which have occurred since then. Despite hopes that recent developments in electronics, particularly in the field of semi-conductors, might avoid difficulties associated with conventional metal-to-metal contacts, it is clear that basic problems in electrical contacts are still with us. Some practical problems have been solved, or circumvented, but others have appeared in new forms. However, considerable advances have been made in our knowledge of the physics of the molten metal bridge, its formation, growth and final destruction, and of the miero-are to which it appears to give rise in certain conditions. At the same time, work in this field is enlarging our knowledge of the properties of metals at very high temperatures.

Another important conclusion can be drawn from this most interesting and worth-while symposium. In the conference of 1952 it was not clear that the engineer concerned with the operation of contacts, and the physicist concerned with fundamental processes, were attacking the problem together; at the present conference there appeared to be far closer liaison between the physicist and engineer, and, further, it was apparent that the designer now fully appreciates methods of approach depending on investigation in controlled conditions of, for example, ambient atmosphere and surface state.

Dr. J. Topping, principal of the Brunel College of Technology, who welcomed and opened the conference, is to be congratulated on the excellent arrange. ments.

\section{GAS CHROMATOGRAPHY}

$\mathrm{T}$ HE Gas Chromatography Discussion Group held its third annual general meeting on April 21 at the University of Birmingham. Membership had risen by 75 during the preceding year to 346 , including 94 from 18 countries other than Great Britain.

Highlights for the year had been the publication of the first two volumes of Gas Chromatography Abstracts, and the very successful third international symposium at Edinburgh the previous June which had attracted more than five hundred delegates from twenty countries. The Proceedings had been published in a 466-page volume before the end of the year.

The group is planning another informal symposium in the autumn, and arrangements for the fourth international symposium, this time in Hamburg during June 13-16, 1962, are already well advanced.

The Retention Data Sub-Committee reported that very little data had been submitted to them, and after considerable discussion agreed to consider the usefulness of relative retention data, which require less rigorous control of conditions and would probably be more readily available than the absolute data they had been seeking.

The scientific section of the meeting opened with a welcome by Prof. R. C. Robb.

The first paper was presented by Mr. M. B. Evans on the relation between the retention volumes of unsymmetrical compounds and cognate symmetrical ones. The work has since been published in the Journal of Chromatography ${ }^{1}$.

Mr. C. E. Roland Jones discussed technical details in the examination of pyrolysis products, describing a micro-apparatus for use with the Pye argon chromatograph. He illustrated its use in the identification of plastics, especially those which were not amenable to identification by infra-red spectroscopy.
Dr. R. P. W. Scott discussed the effect of temperature on resolution both theoretically and in the light of experimental results. $\mathrm{He}$ showed that for any required separation there was an opiimum temperature for a given film thickness and this was more marked with thick films of stationary phase than with thin ones; conversely there was an optimum thickness for a given temperature and an optimum combination of both for minimum analysis time:

Dr. I. Halasz read a paper entitled "Quantitative Analysis of Hydrocarbons with Capillary Columns and Flame Ionization Detectors". He had investigated thoroughly a large number of factors affecting quantitative accuracy, and designed a stream splitter which apparently eliminated the uncertainties of previous models since the scores of tabulated results which he produced showed a consistent accuracy of about 1 per cent.

In the discussion which followed, Dr. Kovats produced some quantitative results from $2 \mu \mathrm{l}$. of rose oil on an unusually wide capillary column used in conjunction with a tungsten filament katharometer. Efficiencies of 40,000-100,000 theoretical plates had been obtained from such columns.

The final paper by J. G. A. Hölscher of the University of Eindhoven was presented by Dr. M. Van Swaay. He was able to show that ionization in argon detectors could be caused by photons from a pulse discharge. Such a discharge caused a current to flow between two electrodes in a mixture of argon and is hydrocarbon, with a time lag characteristic of the velocity of photons rather then metastables, ions from the discharge being screened off by a series of grids.

S. J. HAwKeS

1 J. Chromatog., 5, 300 (1981). 